\title{
Study on Risk Identification and Prevention of Power Transformer Based on Sampling Inspection Theory
}

\author{
TianShu $\mathrm{Bi}^{1}$, JinMeng Chen ${ }^{2}$ and Meng Sun ${ }^{3}$ \\ ${ }^{1}$ North China Electric Power University \\ ${ }^{2}$ North China Electric Power University, State Grid Materials, Company Limited \\ ${ }^{3}$ State Grid Materials Company Limited \\ ${ }^{1}$ sky1934@163.com, ${ }^{2}$ chenjinmeng@sgm.sgcc.com.cn
}

\begin{abstract}
Power transformer is one of the key equipment for power grid, and its quality has important effects to the security, stability and economic operation of the power grid. The government sampling inspection pass rate of $10 \mathrm{kV}$ power transformer is less than $80 \%$ in China, which causes serious impact to the product quality and brings serious security risks. It has great significance to study on the risk identification and prevention method. In this paper, the sampling inspection theoretical analysis of power transformer is carried out with the mathematical statistics and probability theory. Its application in the quality risk identification is studied on. The risk prevention effect of the sampling inspection is studied based on game theory. It is used both on the large scale power transformer and distribution transformer. The sampling inspection has the characteristics such as flexibility, randomness, science, and economics. It can be used in large range with flexible way, especially for the difficult test items. Random is the foundation for the scientific sampling inspection. The approach determines that it can reflect the population quality level with small cost, which has obvious economic benefits. In practice, sampling inspection should focus on the key aspects, including the design of sampling inspection plan, the selection of the sampling mode, the cost and the corresponding punishment.
\end{abstract}

Keywords: power transformer, sampling inspection, risk identification, risk prevention

\section{Introduction}

Power transformer is one of the key equipment for power grid, and its quality has important effects to the security, stability and economic operation of the power grid. In recent years, China electricity equipment enterprises increase investment, expand the throughput, which causes the power transformer market overcapacity and fierce competition. Especially for the distribution power transformers, with low technical threshold and lots of production enterprises, the market competition intensity is more than 5 to 1 [1]. In order to take the market share, the enterprises take low price competition strategy. Some hold down cost deliberately. A few enterprises use the inferior raw material (such as instead of copper wire with aluminum, used silicon steel sheet) during the production process in order to reduce the costs, which causes the loss, partial discharge and temperature rise of power transformers unconformity. The different technical levels of the production companies may also bring quality risk to the power transformer. All of those make a potential thread to the safe and economic operation of the power grid. It has important significance to study on the risk identification and prevention of the power transformer. 
Sampling inspection is an important means of quality management for users. It has obvious advantages to the devices with huge numbers, complicated detect techniques. Through scientific design, it can identify the quality risk of the power transformer, and effective prevent can be taken. The sampling inspection of power transformer involves complicated theory, lots of links specific practices. It has important significance to study on the theory and practice of sampling inspection.

\section{Analysis of Power Transformer Quality State}

The government entrusts the specialty testing institution to inspect the $10 \mathrm{kV}$ power transformer by sampling from 2009 to 2012. The testing items include measurement of winding resistance, voltage ratio and check of phase displacement, short-circuit impedance and load loss, no-load loss and current, separate source AC withstand voltage test, shortduration induced $\mathrm{AC}$ withstand voltage test, temperature rise, measurement of partial discharge and insulating oil test. $12710 \mathrm{kV}$ power transformers are tested, 39 of them unconformity, where the pass rate is less than $80 \%$. The detail information is shown in Table 1.

Table 1. The Sampling Inspection Pass Rate in 2009 to 2012

\begin{tabular}{|c|c|c|c|}
\hline Date & Total sample & conformity & Pass rate \\
\hline 2009 & 29 & 22 & $75.9 \%$ \\
\hline 2010 & 29 & 23 & $79.3 \%$ \\
\hline 2011 & 29 & 20 & $69.0 \%$ \\
\hline 2012 & 40 & 33 & $82.5 \%$ \\
\hline total & 127 & 88 & $77.2 \%$ \\
\hline
\end{tabular}

The unconformity items mainly include temperature rise, load loss, no-load loss and partial discharge.

\subsection{Temperature Rise}

Temperature rise test checks the $10 \mathrm{kV}$ power transformer heat, which is determined by the loss of it. For the oil-immersed type $10 \mathrm{kV}$ power transformer, the influence factors of cooling include product structure, winding up state, oil tank capacity and radiator area, oil circulation. For the dry-type $10 \mathrm{kV}$ power transformer, it is related to the air ventilating duct of core and windings, insulation wrapping, resin-casting.

Power transformer temperature rise test belongs to type test, and few enterprise tests the item before its delivery. It is difficult to detect the defect. Due to the irregular market competition, some enterprises reduce the oil tank capacity and radiator amount, decrease the design margin of conductor and core, and even use the inferior materials, in order to reduce the cost. All of that result in excessive temperature rise of the power transformer, which will accelerate the aging of the insulation materials. It also affects the power transformer useful life, security, reliability, and even leads to short-circuit, accident, which brings safe hidden trouble to the user.

\subsection{No-load Loss and Load Loss}

The no-load loss of power transformer mainly comprises hysteresis loss and eddy-current loss. Hysteresis loss depends on the silicon sheet steel materials. Eddy-current loss is related to the flux density, thickness of silicon sheet steel and the frequency. The load loss of power 
transformer is mainly consisted of windings and leads resistance loss. The additional losses caused by leakage flux take very small proportion [11]. The unconformity of those items is mainly because of enterprise's dishonest behavior. Some enterprises decrease the design margin, without considering the raw materials and production process deviation, in order to reduce the materials cost.

It is shown that the quality risk of the power transformer is still high from the state sampling inspection. The sampling inspection can identify the quality risk in a certain extent, but it cannot prevent the risk or improve the quality of the transformer.

\section{Quality Sampling Inspection Theory for Power Transformer}

Test is aim to determine whether the product or process is qualified, where one or more characteristics are measured, checked or tested, and the results in comparing the requirements. Sampling inspection tests the product or process with the taken samples. Scientific sampling inspection is based on the statistical theory. Due to lack of reliable theoretical basis, other sampling inspection is difficult to predict the level of acceptance of the average quality of products. It is also difficult to estimate the risk of both supply and demand. To obtain a representative sample is the key to determine whether the conclusions accurately reflect the objective conditions

\subsection{Sample Error and Sample Size}

The sample error is the deviation of the sample and population. It is deviation of the sample mean $\bar{x}$ and the population mean $\mu$. The value of the sample error is determined by the sample size $n$.

The factors of sample size include the population deviation, tolerance range, the sampling type and the confidence interval.

\subsection{Operating Characteristic Curve}

The sampling plan is the combination of the sample size and associated acceptance criteria. It is related to the population $N$, sample $n$, acceptance number Ac and rejection number Re. The simple sampling plan needs only determine the $n$ and Ac [12]. The sampling inspection can be classified to single sampling inspection, double sampling inspection, multiple sampling inspection and sequential sampling inspection.

The sampling characteristic function $P_{\mathrm{a}}(p)$ describe the relation of the product quality $p$ and the acceptance probability $L(p)$, which is also called OC curve. The acceptance probability of hyper geometric distribution is as follow:

$$
P_{\mathrm{a}}(p)=L(p)=\sum_{d=0}^{A c} H(D ; n, D, N)=\sum_{d=0}^{A c} \frac{C_{N-D}^{n-d} C_{D}^{d}}{C_{N}^{n}}
$$

Where $D$ means the total nonconforming, $d$ means the sample nonconforming

Analysis shows that the larger the $N$, the sampling plan is wider, but little effect on OC curve. The larger the sample size $n$, the steeper the curve, the sampling plan is more rigorous. Due to the large variation range for $n$, it makes the greatest impact on the curve. When $N, n$ unchanged, with the increase of Ac, the plans become wider [13]. 


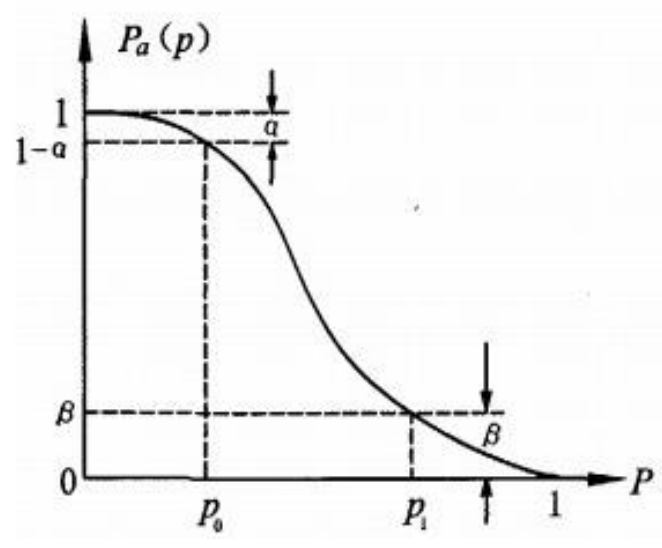

Figure 1. The Traditional OC Curve and Risk

$p_{0}$ means the acceptance quality level, $p_{1}$ means rejection quality level.

When the lot quality $p \leq p_{0}$, the acceptance probability $P_{\mathrm{a}}\left(p_{0}\right)=1-\alpha$

When the lot quality $p \geq p_{1}$, the acceptance probability $P_{\mathrm{a}}\left(p_{1}\right)=\beta$

Where $\alpha$ means producer's risk,

$\beta$ means consumer's risk

The sample size $n$ affects the accuracy and economy of the sample plan directly. The multiple sampling inspection can make the average sample number $\operatorname{ASN}(p)$ smaller.

For the single sampling inspection $\operatorname{ASN}(p)=n$;

For the double sampling inspection $\left(n_{1} / A c_{1}, R e_{1} ; n_{2} / A c_{2}, R e_{2}\right)$ :

$$
\operatorname{ASN}(p)=n_{1}\left[L_{A c_{1}}(p)+L_{R e_{1}}(p)\right]+\left(n_{1}+n_{2}\right)\left[L_{A c_{2}}(p)+L_{R e_{2}}(p)\right]
$$

\subsection{The Principle of the Sampling by Variables}

For the sampling inspection by variables, the quality characteristic can be detected in a continuous scale, and the measured values are compared with the requirements. It can be classified to two types by the quality index as total mean and total nonconforming. For the specification limit, it can be classified to upper specification limit, lower specification limit and double specification limit [14]. The following is upper specification limit example with the $\sigma$ method.

While $\bar{x} \leq k_{U}$, it is accepted,

$\bar{x}>k_{U}$, it is rejected.

Where sample mean $\bar{x}=\frac{1}{n} \sum_{i=1}^{n} x_{i}, n, k_{U}$ undetermined parameters.

Standardized, and solving

$$
\left\{\begin{array}{l}
\mu \leq \mu_{0 U} \text { 时, } P_{\mu}\left(\bar{x} \leq k_{U}\right) \geq 1-\alpha \\
\mu \geq \mu_{1 U} \text { 时, } P_{\mu}\left(\bar{x} \leq k_{U}\right) \leq \beta
\end{array}\right.
$$

$$
\begin{gathered}
\left\{\begin{array}{c}
n=\sigma^{2}\left[\frac{\Phi^{-1}(\alpha)+\Phi^{-1}(\beta)}{\mu_{1 U}-\mu_{0 U}}\right]^{2} \\
k_{U}=\frac{\mu_{1 U} \Phi^{-1}(\alpha)+\mu_{0 U} \Phi^{-1}(\beta)}{\Phi^{-1}(\alpha)+\Phi^{-1}(\beta)}
\end{array}\right. \\
k_{U}=\mu_{0 U}+\frac{\mu_{1 U}-\mu_{0 U}}{\Phi^{-1}(\alpha)+\Phi^{-1}(\beta)} \cdot \Phi^{-1}(\alpha)=\mu_{0 U}-\frac{\sigma}{\sqrt{n}} \cdot \Phi^{-1}(\alpha)
\end{gathered}
$$


As $k=\frac{1}{\sqrt{n}} \cdot \Phi^{-1}(\alpha)$

The operating characteristic function:

$$
P_{\alpha}(\mu)=P_{\alpha \mu}\left(\bar{x} \leq k_{U}\right)=\Phi\left(\frac{k-\mu}{\sigma / \sqrt{n}}\right)=\Phi\left[\sqrt{n}\left(\frac{\mu_{0 U}-\mu}{\sigma}-k\right)\right]
$$

It is shown that the smaller the $\mu$, the bigger the acceptance probability for the upper specification limit.

\subsection{The Supervision Sampling Inspection Theory}

The supervision sampling inspection is used to protect the product quality and the consumer's benefit, which is taken by the third independent party. It can determine whether the population is acceptable. It is different from the acceptance sampling inspection. The aim of the supervision sampling inspection is not to estimate the quality level of the population, but to find the unqualified products. It concerns whether the negative conclusion is right, and does not guarantee the accuracy of the conforming.

The supervision sampling inspection plan is designed according to the hypothesis test in the Mathematics Statistics. The judgment is based on the little probability event principle. Generally, the little probability event will not happen during one random test. If it happened in the random test, it reasons to suspect the original assumption.

(1) Establish the hypothesis $H_{0}$ and the alternative hypothesis $H_{1}$;

(2) Determine the acceptance region and rejection region of $H_{0}$.

When the hypothesis is right, the rejection probability does not exceed a given value. Where $\alpha$ is called significance level, also type I error.

$$
P\left\{\text { rejection of } H_{0} \mid H_{0} \text { is ture }\right\} \leq \alpha,
$$

In theory, the power transformer quality should reach a certain level, where the quality risk is little. But in practice, the quality risk cannot be ignored for various reasons. The sampling inspections of the power transformer for most test items are belong to the supervision sampling inspection. But for the short circuit withstands ability test and the temperature rise test, it can be seen as acceptance sampling inspection. The sampling inspection has different effect to identify the quality risk with the different test items.

\subsection{Quality Risk Identification of the Power Transformer}

The scientific sampling inspection can reflect the population quality level. The test items are determined by system analysis, which can adjust dynamically due to the quality change. The sampling inspection can identify the quality risk of power transformer for the consumer, while the control method can be taken to prevent the risk.

Risk is defined as the occurrence of an undesirable outcome measure of the probability and severity. Generally:

$$
R=P \cdot C
$$

Where $P$ means the probability, $C$ means the results.

Risk assessment methods include the risk matrix method, the Monte Carlo method, failure modes and effects analysis and event tree analysis [2]. In the field of electrical engineering, the research on risk assessment is mainly concentrated in the electricity market, power systems, network planning [3-9]. For electrical equipment, especially the study of power transformers risk assessment methods is rarely seen. According to the quantitative degree of evaluation results, the risk assessment methods can be classified to three types, namely: 
qualitative risk assessment methods, semi-quantitative risk assessment method and quantitative risk assessment methods.

In this paper, the unqualified rate of the sampling inspection is seen as population quality risk of the power transformer. The unqualified test items are the consequence, which brings different results and treatment measures. From the consumer's perspective, it can identify the quality risk conveniently, while the prevention and control treatment can be taken to reduce the risk.

\section{The Quality Risk Prevention Method of Power Transformer}

Product quality not only constraints by interior of the enterprise, but is also affected by the external environment [10]. The quality problem is not limited to only enterprise its-self; it is also related to the whole society. The key factors affecting the product quality are from of enterprise interior, including the enterprise lead's cognition, quality organization level, worker's actual ability, high quality raw materials, advanced technique and equipment, reliable inspection. The sampling inspection can identify the quality risk of power transformer, but to prevent the risk is not enough.

\subsection{The Quality Risk Prevention Analysis}

The selection mode of the rules for the enterprise depends on the total income, including obeying rules income $R_{l}$, disobeying rules income $R_{0}$, and the probability punishment for disobeying rules $F$. If $R_{l}>\left(R_{0}-F\right)$, the enterprise probably obey the rules; if $R_{l}<\left(R_{0}-F\right)$, the enterprise may not obey the rules $[15,16]$.

The value of $R_{0}, R_{l}$ depends on the enterprise. It can be regarded as fixed in a period. The value of $F$ is proportional to $f_{s}, p_{s}, p_{c}, c_{p}$, namely

$F=f\left(f_{s}, p_{s}, p_{c}, c_{p}\right)$,

Where

$f_{s}$ the frequency of sampling inspection.

$p_{s}$ the probability of finding defects by sampling inspection.

$p_{c}$ the probability of enterprise's problem.

$c_{p}$ the loss because of the punishment.

The values of $f_{s}, p_{s}, c_{p}$ are related to the sampling inspection. The reasonable value of $F$ can be obtained through scientific setting, which makes $R_{l}>\left(R_{0^{-}}-F\right)$.

It can be seen that the punishment is the very important to risk prevention.

\subsection{Adjustment of the Sampling Inspection Parameters}

The scientific sampling inspection should adjust the plan dynamically. $p_{c}$ can be obtained with the history data. $p_{c}$ is proportional to $f_{s}$, which should be higher to enterprise with more problems. $p_{s}$ depends on the scientific sampling inspection method, closely related to the test items. The items should be tested, which are easy to find problem and have serious influence to the security operation, such as the following items: temperature rise test, short-circuit impedance, no-load loss and current, separate source AC withstand voltage test, shortduration induced AC voltage test, measurement of partial discharge. Short-circuit withstand test can be taken to check the power transformer short circuit withstand ability. We also can disassemble the product to check the materials of conductor and silicon sheet steel.It is determined by the punishment measures largely, whether sampling inspection plays the role. The punishment measures should consider the product quality defects and lost, while it can raise the cost of default. 


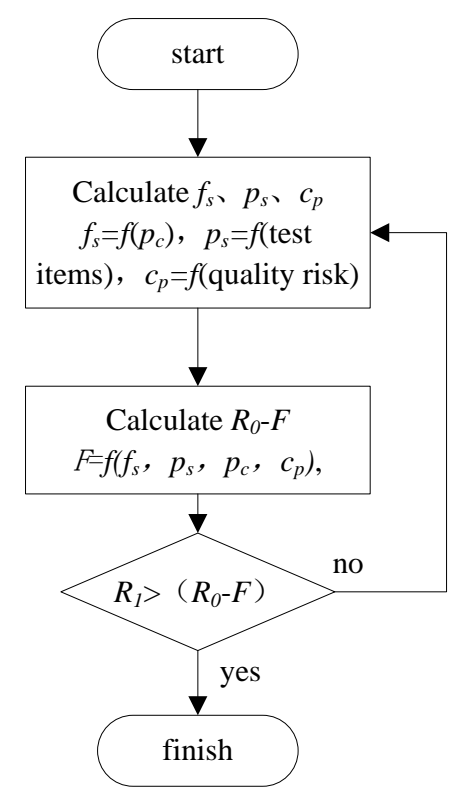

Figure 2. The Flow of Sampling Inspection Plan Design

\section{Examples}

The sampling inspection strategies have larger difference for the different voltage levels. Bellow the sampling inspections of large-scale power transformer and distribution power transformer are analyzed.

\subsection{Large-scale Power Transformer Sampling Inspection}

The manufacture and test techniques of large-scale power transformer are very complexity. The equipment price is high, and the large body weight makes it hard to transportation. All of those make the sampling inspection difficult. In order to detect the technical parameters of power transformer accurately, the major parameter testing system of power transformer is developed by China electric power research institute (CEPRI), which includes the high precision measuring voltage transformer, measuring current transformer, power analyzer, sound level meter, instrument for measuring DC resistance, partial discharge test device and so on. There are mainly seven aspects for the supplier selection principle, including the suppliers with big orders, low price transformer, new supplier, bad performance, domestic silicon steel sheet, key project and more quality problems. The project unit can also apply for sampling test, which will be determined with comprehensive consideration. The results of sampling test are classified into three levels as A, B, C.

5.1.1. Test Item Determination: The principles for test item determination include the necessity, rationality and operability. The routine tests, take-over tests on site and reflection of the project units were considered. Finally, the sampling test items include no-load loss, load loss, sound level measurement, Long-duration induced AC voltage test (ACLD) for $220 \mathrm{kV}$ and above.

It not only has important influence to the economic operation of power transformer for the no-load loss and load loss, but also affects the manufacturing cost obviously. The power transformer market competition is very intense in China, which makes the supplier to lower 
the manufacturing cost as much as possible. It may lead the measured value of no-load loss or load loss larger than the contract value. Even then, because the numerical only can be got from the supplier routine test report, which lack checking by the third party test, it has risk.

The partial discharge has important effects to the long term safe operation of the power transformer. The unqualified rate of partial discharge under ACLD test is much higher than other test items. Because of the test environment disturbance for the take-over test on site, the test result evaluation standard is lower than the routine test. It also has risk for lacking the checking test.

The sound level of power transformer reflects the performance of the silicon steel sheet and the manufacturing technology level. With the improvement of the social environment protection consciousness, the requirement of the power transformer sound pressure level is higher and higher.

5.1.2. Sampling Inspection Analysis: During 2009 and 2012, 95 power transformers of $220 \mathrm{kV}$ to $750 \mathrm{kV}$ were tested by sampling test. The qualified rate of Level A is up to $100 \%$ for recent two years from $84 \%$ of 2009. It is shown that the effects of sampling test are remarkable. The sampling test makes the supplier attach great importance to the quality of power transformer. Since the sampling test, three of power transformer has been classified to Level C, and two of them classified to Level B. The suppliers with Level B and C were punishment in the bidding process and the performing contract correspondingly. All the series treatments make the supplier to improve the production management, process control and testing technology and equipment. The qualified rate of Level A is shown in Figure 3.

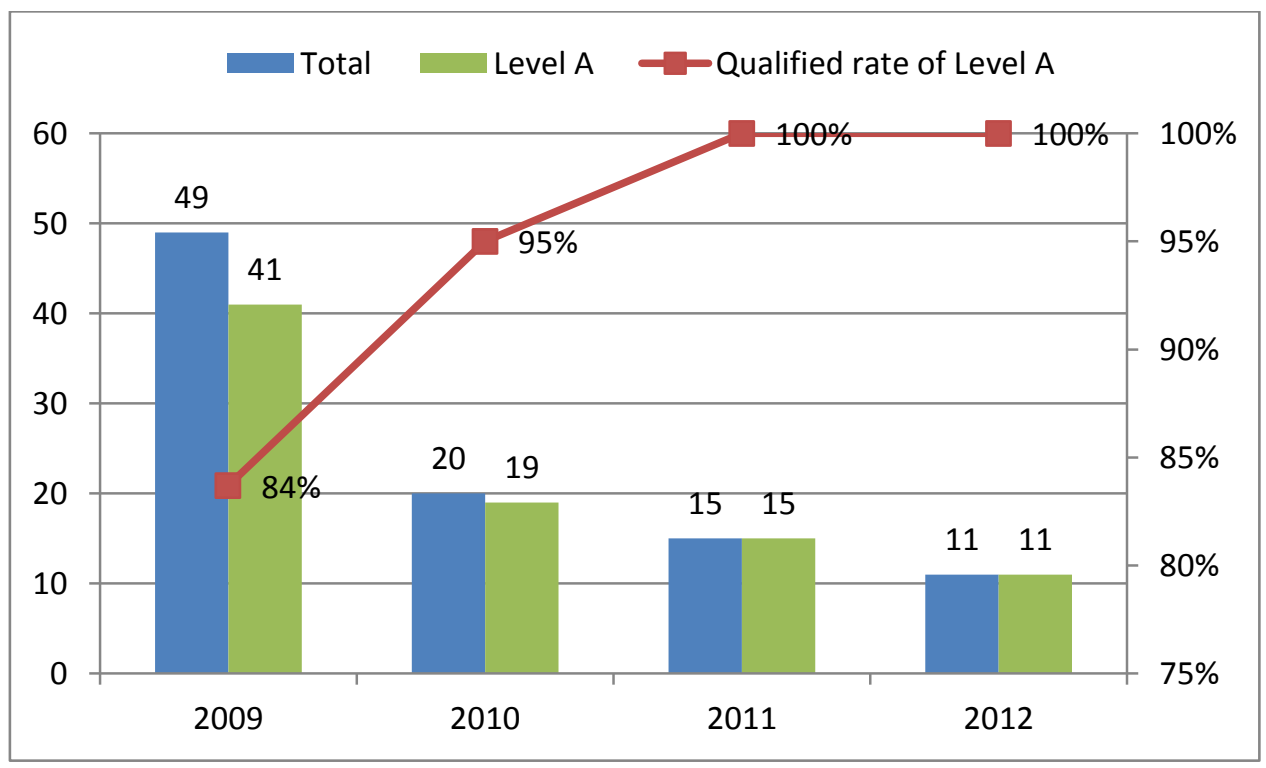

Figure 3. Qualified Rate of Level A

The average of the margin (AM) of the no-load loss, load loss, HV partial discharge, MV partial discharge and sound level from 2009 to 2012 is shown in figure 10. It is shown that the AMs of HV partial discharge, MV partial discharge and no-load loss have the trend of growing up. The AMs of load loss and sound level are at the same level.

It is worth noting that some supplier delayed the sampling schedule casually after receiving the sampling notification, which reduces the effect of sampling test. On the other side, it also 
shows that the sampling test of power transformer brought certain pressure to the suppliers. It has the effect to make the supplier pay more attention to the manufacturing process control and production quality.

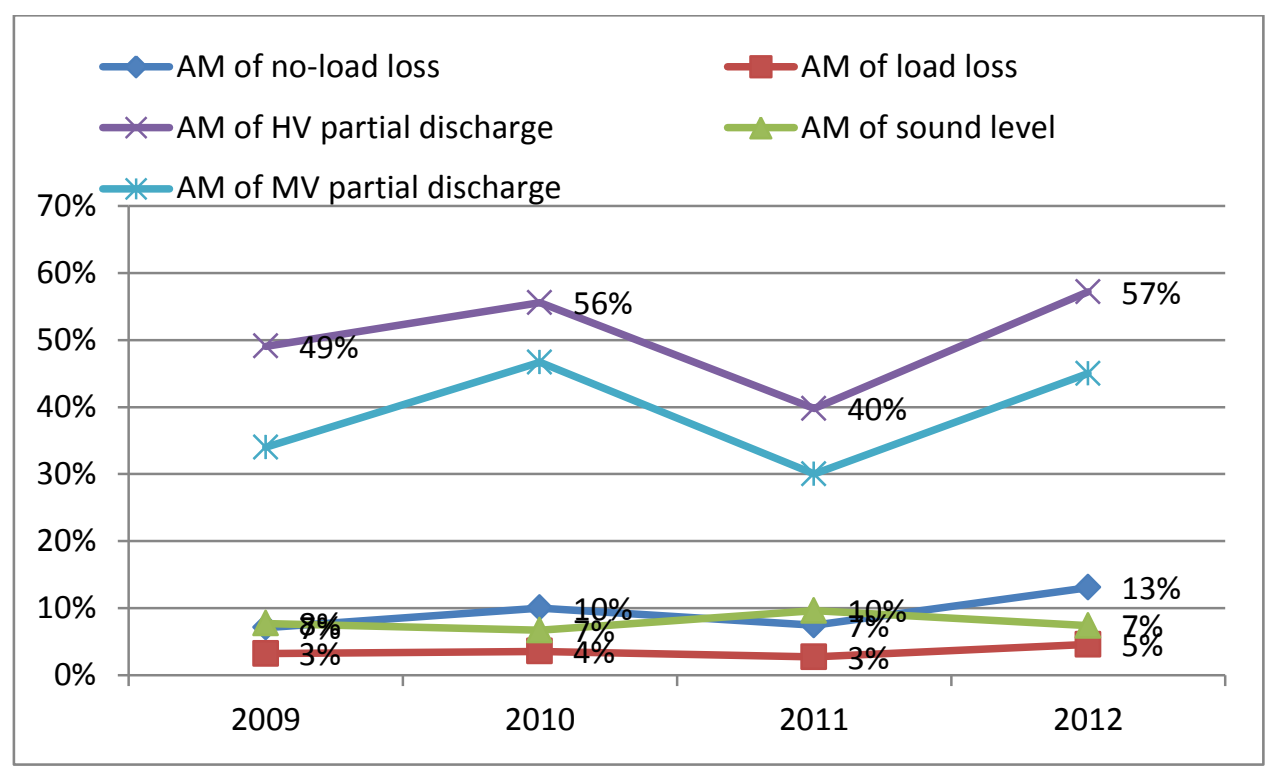

Figure 4. AM of the Four Test Items in 2009 to 2012

\subsection{Distribution Power Transformer Sampling Inspection}

The distribution power transformer's number is huge, and it has lots of enterprises due to the low technique threshold. The sampling inspection is hard to organize.

In 2012, the sampling inspection of DTs was strengthened for SGCC. The items include visual inspection, key performance testing and disassembly inspection. The performance items include no-load current and on-load loss, short circuit impedance and load loss, temperature rise, and so on.

During the sampling inspection, the corresponding punishments were taken to the enterprises for their unconformity product. According to the severity of the sampling unqualified product and the punishment criterion, the treatments of liability for breach of contract, replacement of the batch product were taken. The related suppliers cooperated with the recall or replacement actively. 9578 DTs were sampling inspected in 2012. 660 DTs of that were unqualified with 691 unqualified items. The qualified rate of sampling inspection is up to $93.11 \%$ compared with $61.26 \%$ of 2011 . The unqualified items are shown in Table 2. The unqualified rates of DTs are shown in Figure 5. 
Table 2. The Unqualified Items in 2012

\begin{tabular}{|c|c|c|c|}
\hline Risk type & Test items & $\begin{array}{c}\text { Unqualified } \\
\text { number }\end{array}$ & $\begin{array}{c}\text { Unqualified } \\
\text { rate }\end{array}$ \\
\hline \multirow{7}{*}{$\begin{array}{l}\text { Process } \\
\text { quality } \\
\text { problems }\end{array}$} & Oil tank leakage & 244 & $2.55 \%$ \\
\hline & unqualified insulation wrap & 45 & $0.47 \%$ \\
\hline & Oil tank outlook defect & 30 & $0.31 \%$ \\
\hline & Oil tank not flat & 19 & $0.20 \%$ \\
\hline & Process size deviation & 15 & $0.16 \%$ \\
\hline & phase sequence error & 13 & $0.14 \%$ \\
\hline & Core directly to ground & 1 & $0.01 \%$ \\
\hline \multirow{4}{*}{$\begin{array}{l}\text { Unqualified } \\
\text { key } \\
\text { characteristics }\end{array}$} & No-load current and no-load loss & 119 & $1.24 \%$ \\
\hline & Short circuit impedance and load loss & 85 & $0.89 \%$ \\
\hline & Lighting impulse test & 8 & $0.08 \%$ \\
\hline & Temperature rise test & 44 & $0.46 \%$ \\
\hline \multirow{3}{*}{$\begin{array}{l}\text { Unqualified } \\
\text { materials }\end{array}$} & Aluminum coil & 53 & $0.55 \%$ \\
\hline & Scrap silicon steel sheet & 8 & $0.08 \%$ \\
\hline & Unqualified insulation oil & 7 & $0.07 \%$ \\
\hline
\end{tabular}

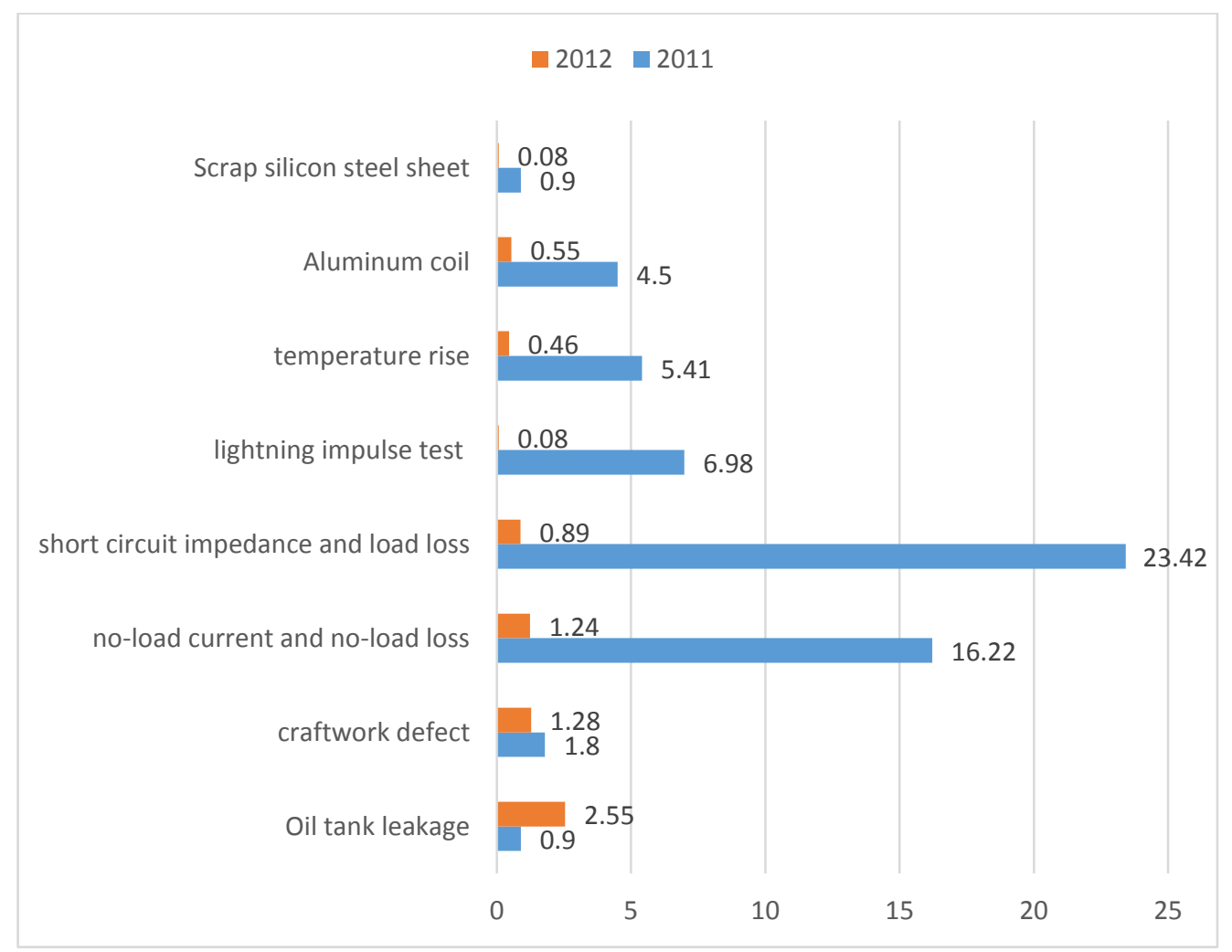

Figure 5. 2011-2012 DTs Unqualified Rate of Sampling Inspection

In order to prevent the quality risk, the punishment was strengthened for the quality defects. There are more than 300 companies were punished correspondingly. 


\section{Conclusions}

In this paper, the sampling inspection theoretical analysis of power transformer is carried out with the mathematical statistics and probability theory. Its application in the quality risk identification is studied on. The risk prevention effect of the sampling inspection is studied based on game theory. It is used both on the large scale power transformer and distribution transformer. The sampling inspection has the characteristics such as flexibility, randomness, science, and economics. It can be used in large range with flexible way, especially for the difficult test items. Random is the foundation for the scientific sampling inspection. The approach determines that it can reflect the population quality level with small cost, which has obvious economic benefits.

The research and practice show that scientific sampling inspection design can identify the quality risk of power transformer. It also can reflect the population quality level of the power transformer, but cannot prevent the quality risk by itself. The corresponding punishment should be taken in order to realize risk prevention. In practice, sampling inspection should focus on the key aspects, including the design of sampling inspection plan, the selection of the sampling mode, the cost and the corresponding punishment. Sampling inspection has become an important means of power transformer quality risk identification and prevention.

\section{References}

[1] L. Wu and S. Zhang, "Transformer product quality rise up largely in China", lighting newspaper, vol. 4, no. $25,(2012)$.

[2] B. Kai and L. Richeng, "Study on risk assessment of transmission and distribution equipments", electric power, vol. 42, no. 10, (2009), pp. 48-51.

[3] J. Xu, P. B. Luh, F. B. White, E. Ni and K. Kasiviswanathan, "Power portfolio optimization in deregulated electricity markets with risk management", IEEE Transactions on Power Systems, vol. 21, no. 4, (2006), pp. $1653-1662$.

[4] D. Das and B. F. Wollenberg, "Risk assessment of generators bidding in day-ahead market", IEEE Transactions on Power Systems, vol. 20, no. 1, (2005), pp. 416-424.

[5] L. Guangbin and R. Billinton, "Operating reserve risk assessment in composite power systems", IEEE Transactions on Power Systems, vol. 9, no. 3, (1999), pp. 1270-1276.

[6] A. P. Douglas, A. M. Breipohl, F. N. Lee and R. Adapa, "Risk due to load forecast uncertainty in short term power system planning", IEEE Transactions on Power Systems, vol. 13, no. 4, (1998), pp. 1493-1499.

[7] A. L. Orille-Fernandez, N. Khalil and S. B. Rodriguez, "Failure risk prediction using artificial neural networks for lightning surge protection of underground MV cables", IEEE Transactions on Power Delivery, vol. 21, no. 3, (2006), pp. 1278-1282.

[8] H. Tsun-Yu and L. Chan-Nan, "Risk informed design refinement of a power system protection scheme", IEEE Transactions on Reliability, vol. 57, no. 2, (2008), pp. 311-321.

[9] L. Wenyuan, Z. Jiaqi, X. Kaigui and X. Xiaofu, "Power system risk assessment using a hybrid method of fuzzy set and Monte Carlo simulation", IEEE Transactions on Power Systems, vol. 23, no. 2, (2008), pp. 336-343.

[10] Z. He, P. Wan and C. Li, "Manufacturing industry quality control situation and strategy in China", Journal of Tianjin University (social science), vol. 4, (2010), pp. 18-19.

[11] Y. Xie, "Power Transformer Manual", China machine press, Beijing, (2008).

[12] Y. Zhenfan, M. Yilin and F. Shiyong, "Product quality sampling inspection", China standard press, Beijing, (2008).

[13] X. Haihong, "Sampling inspection technology", China Metrology Press, Beijing, (2005)

[14] Z. Yuzhu, "The planning and implementation of supervision sampling inspection", China standard press, Beijing, (2007).

[15] R. Gibbons, “A prime in game theory”, China Social Sciences Press, Beijing, (1999).

[16] Z. Sun, "Research on the problem of regulation of product quality in China - an angle of law-andeconomics", Jilin University, jilin, China, (2006). 

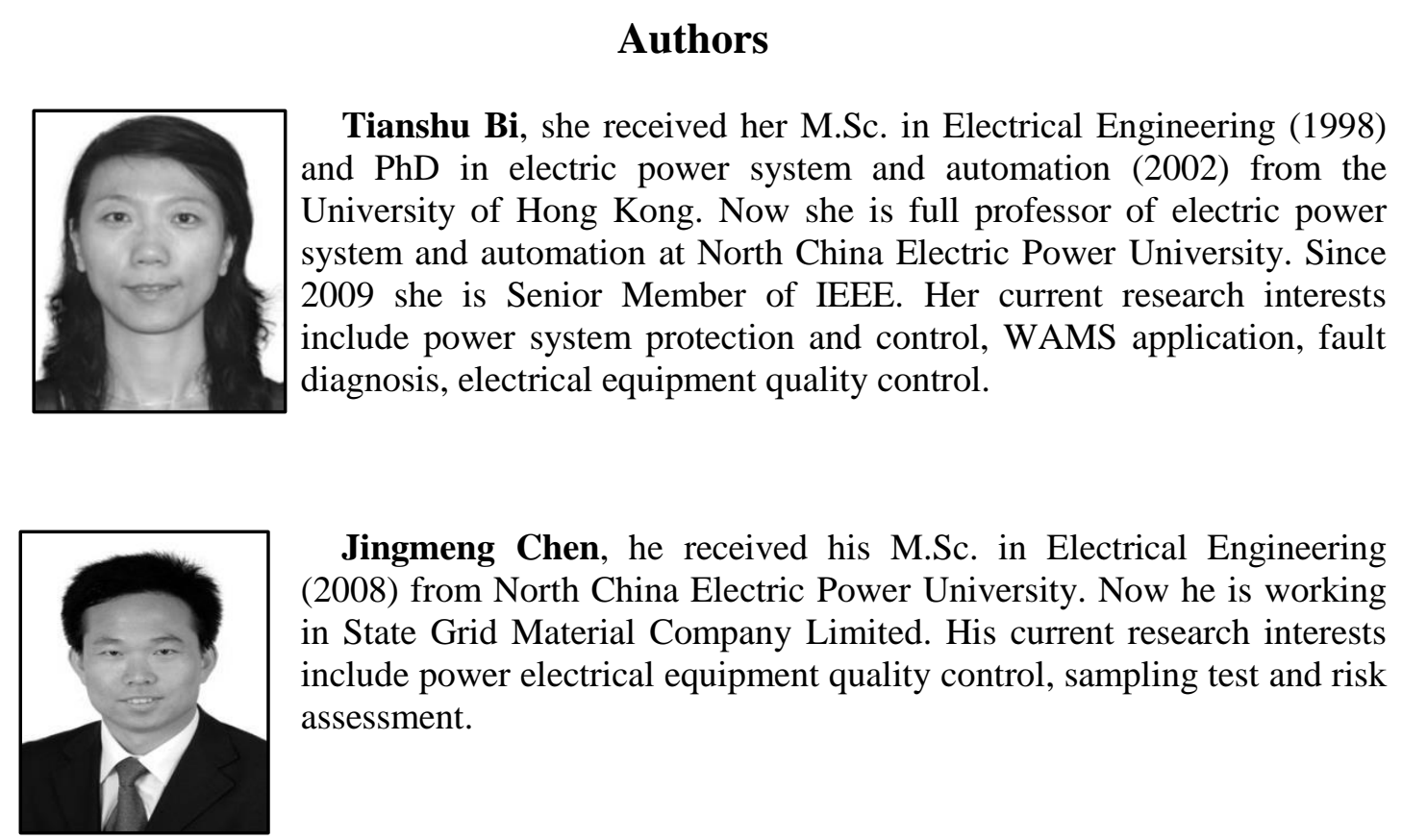

Jingmeng Chen, he received his M.Sc. in Electrical Engineering (2008) from North China Electric Power University. Now he is working in State Grid Material Company Limited. His current research interests include power electrical equipment quality control, sampling test and risk assessment. 